\title{
The Teaching of the Hebrew Language in Arab Schools: The Effect of Teaching Methods on Spelling Errors among Students in the Village of Al-Ghajar
}

\author{
Janan Faraj Falah \\ Arab College for Education, Haifa, Israel \\ Email: jananf81@gmail.com
}

How to cite this paper: Falah, J. F. (2017). The Teaching of the Hebrew Language in Arab Schools: The Effect of Teaching Methods on Spelling Errors among Students in the Village of Al-Ghajar. Creative Education, 8, 2535-2547.

https://doi.org/10.4236/ce.2017.815175

Received: November 8, 2017

Accepted: December 26, 2017

Published: December 29, 2017

Copyright $\odot 2017$ by author and Scientific Research Publishing Inc. This work is licensed under the Creative Commons Attribution International License (CC BY 4.0).

http://creativecommons.org/licenses/by/4.0/

\begin{abstract}
This article examines the phenomenon of spelling errors and poor expression in the Hebrew language among students of the village of Al-Ghajar, students who finish their duties in the Hebrew language at school and still lack the basis of the language, unable to speak the language, to take a speech at lectures, or grammatically write without mistakes. This phenomenon is common among the Arab population in general, and among the students from the village of Al-Ghajar in particular. The research examines the teaching methods of the Hebrew language in Arab schools, in Al-Ghajar particularly, in order to learn the origin of these common errors in spelling and grammar among students. The Hebrew language is considered a foreign language among the Arab villagers, especially the village of Al-Ghajar, which is located "at the foot" of Mount Hermon and lack of access and exposure to Jewish population, except for residents who have to maintain relations with public services, usually in the city of Kiryat Shmona. For most of the village residents, the Jewish culture is irrelevant, an element that affects the poor language skills, leads to poor writing and spelling. Accurate learning processes affect positively and significantly the skills of writing and speaking of a language.
\end{abstract}

\section{Keywords}

The Perception of Students, The Hebrew Language as a Second Language, Identity, Minority, Spelling Errors among Students, Al-Ghajar Village, Golan Highs 


\section{Theoretical Background}

Al-Ghajar is an Alawite-Shi' ite village on the "foot" of Mount Hermon. The village is divided into two sections, the first one is annexed to Israel under the Golan Heights Law in 1982, and the other part remained under the rule of Lebanon. The meaning of the word Al-Ghajar " الغجر in Arabic is "Gypsies", for the village was ruled by many foreign powers, from the Ottoman empire to the French governing.

At time of the Ottoman Empire, the Middle East was divided into provinces and major cities. At that time, the Village administratively was connected to the village of Majdal Shams and municipally to the city of Quneitra (Hilf, 2006). In 1967, after the Six Day War, the district of the Golan Heights had undergone many changes, and part of it was conquered by the Israeli IDF and became an Israeli territory, while the other part remained in Syria. Although the village of Al-Ghajar is located within the territory of the State of Lebanon, the Lebanese refused to accept it, claiming that the Alawite origin of its residents naturally make them pat of Syria's citizens. After the war, the village was independent for two months, until it was claimed by the Israeli Army. Its residents did not resist the Israeli army, for Lebanon Government did not accept their citizenship due to their Alawite ethnicity. Later on, they had received an Israeli ID card, accepted Israeli Government and institutions as well as the State's educational dictation, and its students had started using the Druze school curriculum and programs (Zubeida, 1987).

As stated above, the Village's students had begun learning the Israeli curricula of the Arab and Druze sector, including the Hebrew (State) language as a second language from third to twelve grades, and the teachers were trained at the Israeli academic institutions.

In contrast to other villages in the Golan Heights, such as Majdal Shams or Mas'ade, the entrance to the city is dependent upon presentation of an ID card, and foreigners cannot enter the city without military prior coordination. In 1982, the Village was official annexed to Israel by the Law of the Golan Heights, as the other Druze villages (of the Golan Heights) and its residents were given an Israeli ID card (Strassman, 2010).

The education system have also been altered since 1967, a primary school for grades one to six was built and today includes 335 students, high school by the name of Salman Khatib was also built, it has approximately 400 students who take the matriculation exam of Bagrut each year, as other students from other parts of the country do. The school is under the supervision of the North District of the Ministry of Education, with an effort to integrate the students to the industry since January 2009. The students have special programs which contain lectures of dominant Figure ures from the industry, tours to industrial plants and projects, in order to work in the industry after graduating school, to improve and contribute socially and economically to the State in general and to the Village in particular. 


\section{Introduction}

\section{1) The characteristics of teaching of Hebrew in the Arab sector including in Al-Ghajar}

The Hebrew and Arabic language belong to the group of Semitic languages, historically related to each other. In addition, both languages, Hebrew and Arabic have undergone adaptation processes of words from each other (Merie, 2013), yet, it is considered a second language, which large sections of the Arab society, especially among the villagers, is not common, although it is compulsory subjects with 5 points credits in the matriculation exam (the Bagrut).

It is important to take into consideration at the stage of teaching of a second language, the student's age, one's cognitive development and the extent of mastering the native language, in order to predict success in mastering a second language (Aliyan \& Abu Hussein, 2012).

The methods of teaching the Hebrew language as a second language in Arab schools are affected by various factors. It has basic principles of literacy orientation, a special emphasis on speech (oral expression), the aesthetics of Hebrew literature, including aiming for ideological, social and civilian purposes of exposing the Arab students to Jewish cultural heritage and to be aware to social and cultural sensibilities.

The Arab students learn the Hebrew language and literature three times more than the Jewish students, as was emphasized in the internal report of the Department of Curriculum of the Ministry of Education, the Arab student studying Hebrew language for about 8 hours a week, while the Jewish student only 3 hours per week.

Thus, the Arab student learns the Hebrew language as twice hours than the Jewish one, furthermore, a large part of the contents are irrelevant to the Arab society, hence, with the absence of the right guidance of study method, the material becomes boring and intangible.

The teaching method in most of the Arab schools is general is traditional and repetitive, primarily aimed to emphasize gaining of knowledge and skill proficiency, however, merely few Arab high schools use the method of dialogue and the techniques to cultivate Arab self-identity in the Israeli society (Merie, 2013).

The literature lessons were not deliberately intended to impart the Arab student national values, but rather a tool for providing Hebrew educational targets, not entirely technical. From the beginning, the emphasis was on the explosion of the Arab student to the Jewish heritage and culture and to the development of the Israeli citizenship (Abu-Asbah, Gusi, \& Ben Joshua, 2011). Over time, the subject of the Hebrew language has strengthened at the expense of the subject of the Arab language.

It is important to emphasize that learning methods ate crucial, for it provides strategies for understanding the material and not merely memorizing it, thus, learning becomes meaningful. This Part is under the responsibility of the teachers. Studies on the subject of productive learning indicate that teacher who 
changes the learning method, especially in multi textual subjects, creates better learning experience for the students, the material becomes easier and students are able to absorb more content, as opposed to teacher who uses traditional methods without mastering the material perfectly (Aliyan \& Araida, 2008).

In addition, studies on the subjects of teaching methods and the teachers' condition in the Arab sector, indicate that the common teaching method in Arab schools is traditional and by monologues. The method focuses on the good students with the high grades, students who have gained achievements regardless school, for their high degree of thinking and intellectual skills that are developed in supportive family and social surrounding. This method rather leads to neglect of students with learning difficulties, who greatly are dependent on school.

Moreover, the traditional teaching of the Hebrew language quite affects the extent of knowledge and understanding of the material's cornerstones, for it encourages memorizing and not examination or significant learning, factors which create difficulties among many students.

\section{2) The curriculum of Hebrew literature for the Arab sector}

The Arab education in Israel is an integral part of the general system of education; it runs by officials and decision-makers of the Ministry of Education-the highest authority, not by an Arab Committee or school administrators (Jabareen \& Agbaria, 2010). The lack of autonomy has led to many cases of loss of control of educational objectives, and to denial of rights from the Arab sector to form contents in accordance with the interests of the Arab minority (Jabareen \& Agbaria, 2014). Since the beginning of applying the programs on the Arab schools early in 1949, a Committee for Arab Affairs and a Sub-Committee ware established. The sub-Committee was responsible to the content and material and was authorized to disqualify political inappropriate contents (Al-Haj, 1994). Within the order of this Committee, the textbooks from the period of the British Mandate were replaced, and new books were written by Arab teachers and Jewish speaking Arabic, who were instructed to omit historic and geographic parts in favor of the State.

The Hebrew curriculum for the Arab sector has endured lot of changes since the establishment of Israel; at least four major programs were modified, in accordance to the disciplinary and political contexts. The modifications were expressed in cancelling the matriculation exam, an expansion of optional course units, including insertion of new and modern pieces, minimizing the extent of material and presenting curriculum designed by women (Dahamsha \& De-Malach, 2014).

The first program appeared in 1958, it was criticized for the extent of Bible Studies for Muslim students, instead of teaching the Koran, and thus, it emphasizes the desire to expose the Arab students to the Jewish culture and heritage. The first program included writing of teaching hour in each class, the subjects were organized by age and grade. Each grade included a Bible chapter, literature chapter, newspaper clippings and grammar studies, equal to six units of study.

The second program was published in 1977, the program included the names 
of the Committee's representatives who were appointed to write the program, it also included objectives, learning units, contents and study pieces. There were four basic learning units (Zamir \& Hauptmann, 1959).

The third program was published in 2000, the syllabus of the pedagogical inspector Hunny Musa, was attached to it. It included five academic units, 2 obligatory units, with an option for another linguistic unit and two units of literature (five units in total).

The four programs were posted in 2006 and included all grades, from elementary school to high school. It specifies in detail the study units, their extent and specific objectives for studying literature. The program is of five units, two compulsory subjects (writing and reading comprehension) and three are expansionary (linguistics \& literature). The modification over the years is clear-by the number of study units and subjects' emphasis on literature, writing and reading comprehension. Even the goals have changed and expanded from one program to another. Furthermore, some subjects were minimized and some electives were expanded within the unit, due to a change in world view and perceptions, and by the Arab parents and teachers (Yaoz \& Iram, 1987).

3) The relationship between teaching of Hebrew language and multi-cultural society

The Hebrew language in Israel, along with the Arabic one is the official language, hence, the Arab citizen needs to master this language, for it is the language of all State's institutions. Knowledge of the language enables successful economic and cultural adjustment (Watad, 2011). Knowledge of the language enables proper communication between Arabs and Jews, thus, learning the Hebrew language is crucial for normal relations between the two Nations (Watad, 2011). Suzan \& Dubi (2006) believe that teaching of Hebrew in Arab schools is relatively a success. Allegedly, there is symmetry between the Jewish concept of the Arabic language and Arab students' perceptions of the Hebrew language, both sectors conceive the other language as "a language of confrontation" (Susan \& Dubi, 2006). The Hebrew language in Israeli society is part of the national identity, while the Arab language although is defined as an official language, is not part of the State's institutions nor Jewish schools. The desire is to use the educational system for 'friendship purposes' and common destiny, to maintain the status quo of the Jewish majority with the Hebrew language as the official language, and at the same time to maintain relations with the large minority of Arabs.

The knowledge and speaking of the Hebrew language among the Arab population has increased during time. Gradually and steadily a new, mixed language emerges, in which, the Hebrew language has become a significant component for the Arab students, for they recognize the importance of it for better integration in the Israeli society. Regardless this recognition, the Arab students believe that studying Jewish history and culture are irrelevant for them, the Bible lessons, Hebrew literature and poetry do not interest them, and they "settle" in reading newspapers and watch Hebrew TV shows, they also believe that Jews should also 
learn the Arabic language and culture, for they believe it is the key for better neighborly relations (Abu-Asbah, 2007).

4) The importance in acquiring the Hebrew language for proper writing processes among the students of the village of Al-Ghajar

Native language evolves over years, infants begin to speak simple words and sentences at the ages of one and two years old, and their vocabulary and skills constantly develop intuitively, until entering school. These skills continue to improve gradually through reading (of books and texts). Many linguists argue that exposure is the essential component for an acquisition of language skills; weather it is native, secondary or third language. Other key elements in the process are interactions by talking and writing (Doviner, 2012). The Arab children in Arab schools begin to study the Hebrew language in the third grade, yet, they are still not exposed enough to the Jewish society and the Hebrew language, especially in non-mixed settlement.

The relations with the Jewish population is minimal in comparison to the Arab students within the mixed cities, studies prove that learning of foreign languages is relatively easier if the students hold positive attitude in comparison to students with negative and resenting attitude (Doviner, 2012).

It is important to note that the process of the language acquisition involves writing, an integrated element of language acquisition, a direct phase after the development of the reading and speech skills, within other linguistic processes of psychomotor and biochemical that are developed in the course of learning. The process is affected by the development and experience of the child at different learning phases of listening, speaking and reading.

The writing involves complex operation, for it involves number of processes on the sequence, such as paying attention, continuity, simultaneous performance ability and high cognitive abilities as good memory, language and visual perception, elements which enables a child to function within the family and school (Rosenblum \& Frisch, 2008).

A successful grasp of the Hebrew language would lead to social and occupational secure for the Arab students in terms of academic studies on the one hand, and integrating on the labor market in the future on the other hand, for this is the key for better communication at workplace. A Lack of language leads to lack of self-confidence, a barrier which prevents from the young people of the village of Al-Ghajar to apply to certain jobs, or rather take over positions outside the village. It is worth noting that most of the businesses in the Arab sector are family business, this parameter is prominent in the village, for most of the men are working in the family business while women are not employed for social and traditional reasons. However, a person who does not find work in the village has to work outside the village in big factories, whereas knowledge of the Hebrew language is significant (Marom, 2014).

It should be noted that learning of the Hebrew language is aimed to assist the Arab students not only in managing an interaction with the State's institutions and authorities, but also for using of mass media, which is primarily in Hebrew. 
Hebrew is needed on a daily basis, for successful conduct within the social environment and at work (Golan, 2014)

As mentioned above, dominating the spoken language also assists the process of writing. The students of Al-Ajhar do not acquire the Hebrew language properly for two main reasons: the learning is not extended to other subjects, furthermore, students do not use the language outside school and are not exposed to it outside school. Another reason for the lack of knowledge is political. The village residents are well aware to the political conflict and their political unsecured national state. The Hebrew language is considered the language of the conqueror and that is why a minimal use of the language is the best solution within the family. Thus, political and social reasons affect grasping of the Hebrew language properly and fluently, as well as affecting the village Youngers integration.

The students of Al-Ghajar, like many Arab students in Israel, learn the basics of the Hebrew language in order to get to know the values and history of the Jewish nation, a one-sided exposure of Arabs to Jewish culture leads to one-sided dependence of the Arab population and to an absence of integration and adjustment to the Israeli mentality, yet, they are well aware to social modernization and are taking part in these processes (Abu-Asbah, Gusi, \& Ben Joshua, 2011).

The teaching method in the Arab schools is frontal not just in the subject of Hebrew. Most of the schools in the sector emphasize the importance of knowledge and training, without emphasizing the importance of dialogue and identify nurturing techniques (Pasternak, 2003). A change of the educational and social approach in Arab schools, would allow students to be more involved and better citizens in the future, to integrate socially and objectively without barriers.

\section{Methodology}

\section{The Research questions:}

1) What characterizes the learning method in the village's school? And how do students perceive the Hebrew as a second language?

2) What are the difficulties encountered in writing? And how these difficulties affect the students' writing?

\section{Research methods:}

The study will be conducted by in-depth interviews, a common method in qualitative research, assisted by tests, in order to provide more accurate findings for the followed question.

The qualitative research focuses on graduating students who took the matriculation exam in the Hebrew language, in order to examine their cope with the language's aspects at school and later on in the academy.

\section{The study population:}

The study examines 15 students from the village of Al-Ghajar in the academy. I presented the research objectives and they all agreed to participate in the research. 


\section{Findings}

Writing is an important mean for communication. In spite of the increasing use of computers at schools and in higher educational institutes, the students still need writing skills in order to express their knowledge (Viteraov, Israeli, \& Bar-Ilan, 2014). In order to examine the quality of writing, we have conducted tests adjusted to the students' age; the tests include assessments of spelling and writing skills.

Most interviewees (12) had difficulties in the Hebrew language at school, claiming that the Hebrew literature and contents differ tremendously from their world and culture. Hassan, a 22 years old student of Economics at Tel Aviv University, explains that during his school years he did not learn the Hebrew language out of curiosity or motivation but as a result of obligation, for the Hebrew language is compulsory subject needed for obtaining the high school diploma (Bagrut).

Khalil, a 20 years old student of Engineering at Ort-Braude, supports Hassan as well, adding that the most difficult period in his life was at school, mostly in the grammar lessons with the special pronouns, conjugation and multiple "binyanim", "the teacher introduced the material, we made some practice and immediately moved on to new material, it was also difficult learning at home, for my parents could not help me at all, I remember that other students had the same problem. I decided for the Bagrut Exam to study only literature and to avoid grammar, my main interest was to pass the Exam with a minimum score".

T., a 22 years old student at the college of Tel-Hai explains the difficulty in learning the Hebrew language at school "I loved learning Hebrew until the $8^{\text {th }}$ grade, before the teaching method had changed and learning became boring. From the $8^{\text {th }}$ grade the teacher asked to divide the notebook into two parts of literature and grammar. The second part was very hard". Today, she feels proud that she had managed to pass the exam, despite the difficulties in the learning process.

Hebrew language lessons were conducted frontally, the teacher read and wrote on board the material that was important for passing the exam, claims Mustafa, a 23 years old student. "These lessons stand in contrast to English lessons, in which the teacher showed us movies and we made the research more interesting and significant. Some of the literary works in English became movies, the same apply for key Figures as Gandhi for example, which were lacking from the Hebrew language that was mainly focused on stories from the Bible or poems of famous poets like Bialik, Figures and themes that they have no interest in.

An examination of most students' statements proves of their attitude towards the Hebrew language as a second language. All students-interviewees highlight the sense of missed opportunity in studying Hebrew at school, and claim that the studies were only "on paper", for it was not followed by meeting with Jewish students or at places spoken in Hebrew. Moreover, the material did not assist them to speak the language in order to adjust society or to conduct conversations.

T. claims that the first exposure during his school period was when he joined his father at work of construction in Kiryat-Shmona, "I couldn't have a decent 
conversation except for saying 'good morning' or 'hello'. I could not put a sentence in Hebrew and it made me unconfident, afraid to talk that no one would mock me". The major barrier for Arab students in acquiring the language is personal, especially in Al-Ghajar, where people speak the native language solely at home and are not exposed to the Hebrew language at all, it becomes harder later on, when these children have to cope with institutions that are managed in the Hebrew language exclusively (Hendin, 2011).

The shame in making a mistakes creates barriers between many of the village's students and the Jewish population in Israel, and it is emphasized in poor participation of students in many activities outside the village, for example the summer guiding course in the case of Ali, a 25 years old student: "I had friends from the village of Mas'ade and Majdal-Shams who worked as kayak guides in Kfar-Blum and earned good money, they invited me to try working for one they, and I found it very difficult to communicate with the people, there were sentences that I didn't understand and thus, felt helpless, I preferred to work in the family business, although I really wanted to go outside the village".

With respect to the difficulties the students had experienced in writing, both the interviews and the assessment test reveal difficulties in expression and spelling. Most of the interviewees indicated of difficulties to express themselves verbally, and having great spelling mistakes, as 20 years old Maher indicates. $\mathrm{He}$ claims that writing in Hebrew is his weakest side, especially in omitting or adding words correctly, for instance, writing the word "to write" as "to wrate" according to the sound of the word.

Before the test, the subjects were asked to describe the importance of the Hebrew language to their professional success.

12 subjects found the Hebrew language crucial to their future career, yet, 3 students did not find it necessary, and presented some examples of successful stories of village people who do not speak the Hebrew language (Figure 1).

The 15 subjects were asked to write in 10 rows a letter of appreciation to their professor or employer within 10 minutes. The decision to conduct this test was for two reasons; first, to examine the subjects' written expression skills, secondly, to check the number of the spelling mistakes. For some students (12) it took few minutes to organize their thoughts, the rest begun to write the minute they were constructed. It was found that 7 students wrote 10 lines, 3 wrote 6 lines, 3 wrote 4 lines and 2 students wrote 2 lines (Figure 2).

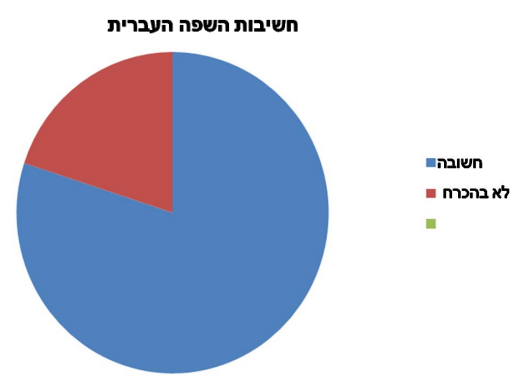

Figure 1. The importance of the Hebrew language. 


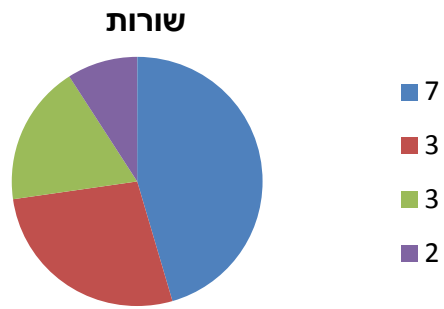

Figure 2. Number of lines.

The examination of the spelling errors reveal that most of the mistakes are due to language backgrounds, furthermore, many mistakes are created out of poor grammar, or making a mistake in identifying the correct phonetic of the letter. The Hebrew language consists mainly of phonetics, that is to say, each letter has a sound, thus, most of the mistakes results in writing the words as it sounds:

Greeting = grating

Help $=$ hilp

Wish $=$ wash

Bless $=$ bliss

Pleasant $=$ pleasont

freind $=$ frand

Position $=$ passed

Read $=$ rea

Yours $=$ yurs

Eat $=$ at

Work $=$ wurk

Come $=$ cume

Listen $=$ lisan

Join $=$ goin

Heading $=$ building

\section{Discussion}

It is clear that most of the errors above resulted in sound; the students wrote the words by their sound, and adding the letter "I", even though in writing it is a spelling mistake. These cases create confusion, especially if the student is not integrated within the Jewish population and does not have any interaction with the Jewish population, nor talking the language or reading in Hebrew. When these students leave the village, they face different standards and required to speak and write in Hebrew, a barrier which the Arab minority finds hard in general, and the Al-Ghajar students in particular. They find it hard to adjust the academic and other higher institution, for the barrier of the language is always present, especially for the students of the village, who are Syrian oriented, speaking the Arab language solely, under the Israeli army control, and ran by few clans. All these complicated factors the Al-Ghajar student "carries on his back" and have to disassemble once one decides to leave the village. The student has to adapt to different culture and life, to learn to use the Hebrew language in order to suc- 
ceed in the academy, to get used hearing lectures in Hebrew, and to write and express oneself in the Hebrew language. This transition is most difficult for students in their first year in the university, and their grades are affected by the level of managing in the Hebrew language.

B. is a student at The Gordon College, she describes the first time she had to email her lecturer, she did not know how to draft the letter, thus, each word was marked "red" (incorrect) in the computer "it was really confusing, I didn't know what to write the letter and did not find the words at all, finally, I asked my Arab friend from Haifa to write for me, I explained my intention in Arabic and she translated it into Hebrew".

\section{Summary}

The students in the village of Ghajar, as other students in the Arab sector, find themselves in a dilemma regarding the importance of the Hebrew language as a second language. The findings of the research support the difficulties in many aspects of the Hebrew language, whether it concerns grammar or reading comprehension, as well as spelling mistakes. The current curriculum in most of the Arab schools do not motivate Arab students to learn Hebrew, for the contents and subjects are far detached from their lives, hence, unattractive. An alternative assessment or participating in shared projects can stimulate and motivate students; it is most likely that they will acquire the language through mutual work with the Jewish students, exposure to resources in practice or by the computer. The Hebrew language is very important for the students of Al-Ghajar, for it enables working or studying outside the village in the future. If the language is a barrier, they would have to settle in working within the village.

Moreover, the political state of the village greatly affects the integration of these students in the Israeli society, except for the initiation for integrating the high school's student in the industry; the State does not initiate other activities to create greater involvement. Thus, after graduating high school, the students work within the village, and only few graduates work outside the village.

There is no government service in the village, such as MDA services, or other official offices that can expose the residents to the Hebrew language. Another parameter that prevents embracing of the language is the security check in the entrance to the village, in opposite to the Druze villages in the Golan Heights, which succeeded to develop in-country tourism throughout the year, an exposure which had created a need to speak the Hebrew language, in this manner, people managed to acquire a language that was considered to be the language of the enemy.

The village of Al-Ghajar can develop in country tourism as well, especially for its magnificent, pastoral wild nature view of the banks of the Hasbani River, yet, out of security concerns and its closeness to the Lebanon border, the Israeli Jewish citizens avoid entering the village, and as a result, the village remains isolated. This isolation contributes the village's adults, as well as its students, to avoid learning the Hebrew language. 


\section{References}

Abu-Asbah, H. (2007). Arab Education in Israel: Dilemmas of National Minority. Jerusalem: The Floeresheimer Institute for Policy.

Abu-Asbah, H., Gusi, V., \& Ben Joshua, N. (2011). The Identity of Palestinian Teenagers in Israel, Their Identification with the State and the Jewish Culture and Its Meaning in Education. Midat Dapim (Browse Journal and Research in Education of Mofet Istitution), 52, 52-77.

Al-Haj, M. (1994). Preparing of Curriculum to the Arab Population in Israel: Changes \& Recommendations (pp. 1-7). Jerusalem: Floeresheimer Institute.

Aliyan, S., \& Abu Hussein, G. (2012). Student Attitudes towards the Hebrew Language Studies as a Second Language in East Jerusalem Schools. Pages, 53, 101.

Aliyan, S., \& Araida, A. (2008). Report on Attitudes toward Language Acquisition of Hebrew as a Second Language among Golan Students in the Shadow of Annexation. Haifa: Israel. Madrat, 2, 489-526.

Dahamsha, E., \& De-Malach, N. (2014). Hebrew Curriculum to Arab Students: “An Introduction to Israel” for "Socioeconomic Promotion". Giluy-Daat, 6, 67-96.

Doviner, D. (2012). The Right Conditions for Acquiring Languages \& Teaching Language (p. 3). An Invited Review as Background to Experts Team Work in Teaching Arabic to Jewish Students Education.

Doviner, D. (2014). The Importance of the Hebrew Language for Arabs' Integration \& Promotion in the Labor Market (p. 120). Jerusalem: The Ministry of Education, The Department of Publications.

Golan, S. (2014). Teaching Hebrew to Arabic-Speaking Sector-The Transition to Employment Orientation \& Tolerance (p. 128).

Hendin, A. (2011). The Integration of Arab Students in Israeli Higher Education. A Thesis, Jerusalem: The Hebrew University.

Hilf, T. (2006). Wathawik Othmania Haul Al Gulan (p. 122). Damascus: Altaqueen.

Jabareen, Y., \& Agbaria, A. (2010). Education on Hold: Government Policies and Civil Initiatives to Promote the Arab Education in Israel in Nazareth and Haifa: Dirrasath-An Arab Center of Law and Policy. Haifa, Israel: The Faculty of Law, Haifa University.

Jabareen, Y., \& Agbaria, A. (2014). Arab Autonomy in Education in the State of Israel: Rights \& Possibilities. Giluy Daat Journal, 5, 13-17.

Marom, S. (2014). The Importance of the Hebrew Language for Integration and Advancement of the Arab Population in the Employment Market. http://cms.education.gov.il/NR/rdonlyres/F489CADF-99FB-426D-92D7-AE8AAB1E56 94/183414/15.pdf

Merie, E. (2013). Our Hebrew "Integrating the Arabic slang in the Hebrew Slang". Hed the New Studio, Sheet 100, 120-122.

Pasternak, R. (2003). Education in Israeli Society. In A. Ya'ar and G. Shavit (Eds.), Trends in Israeli Society (Vol. 2, pp. 899-903). Tel Aviv, Ramat Aviv: The Open University.

Rosenblum, S., \& Frisch. C. (2008). Dysgraphia-Characteristics and Methods of Evaluation-Contribution of the Study to Clinical Thinking. Israeli Journal of Occupational Therapy, 71, $711 \mathrm{p}$.

Strassman, J. (2010). The Application of Israeli Law to the Golan Will not Prevent an Arrangement with Syria. New Kivunim Journal, 22, 146-152.

Susan, D., \& Dubi, E. (2006). Arab Language-Why? Students Attitudes towards the Lan- 
guage and the Willingness to Learn the Language. Education\& Environment: The Kibbutzim Seminar, 28, 193-206.

Veintraub, N., Wolfson, T., \& Bar-Ilan, R. (2014). Do Students' Executive Roles in Higher Education Require Manual Writing (Vol. 39, pp. 159-178)? Jerusalem: The Hebrew University, The School of Occupational Therapy.

Watad, E. (2011). The Extent of Arabs' Identification with the State of Israel and the Jewish Culture and Its Effect on Education (p. 18).

Watad, E. (2011). The Hebrew Curriculum as a Second Language in Arab Schools for Three Grades. Jerusalem: The Site of Curriculum Planning \& Development.

Yaoz, H., \& Iram, Y. (1987). Changes in the Curriculum of Literature-Comparisons, Studies in Education (pp. 157-170).

Zamir, S., \& Hauptmann, S. (1959). A Portrait of the Jewish Figure Ure in Literature for High School Arab Students' Curriculum (pp. 123-141). Tel Aviv-Yafo: Mofet Institute.

Zubeida, A. (1987). Twenty Years of Educating the Golan Heights. The Ministry of Education \& Culture, the Northern District. 